\title{
Originals
}

\section{Molecular cloning of a group of mouse pancreatic islet beta-cell- related genes by random cDNA sequencing}

\author{
M. Tanaka, R. Katashima, D. Murakami, K. Adzuma, Y. Takahashi, A. Tomonari, H. Iwahana, K. Yoshimoto, \\ M.Itakura
}

Otsuka Department of Clinical and Molecular Nutrition, School of Medicine, University of Tokushima, Tokushima, Japan

\begin{abstract}
Summary To understand the molecular basis of glucose concentration-responsive insulin synthesis and secretion from pancreatic islet beta cells, a group of pancreatic islet beta-cell-related cDNAs was cloned. A pair of cDNA libraries was constructed from a mouse pancreatic islet beta-cell line of MIN6, which was cultured in either high glucose or low glucose media. By applying a random cDNA sequencing approach, 503 and 395 independent species were obtained from a total of 1,011 and 762 clones in the high glucose and low glucose library, respectively. The unknown genes comprised the majority of about $70 \%$ independent clones in both libraries. In Northern blot analysis, $311(69.4 \%)$ of 448 independent
\end{abstract}

clones showed positive signals within $72 \mathrm{~h}$ of autoradiographic exposure. Surprisingly, $150(48.2 \%)$ out of 311 positive clones showed positive signals to MIN6 cells, but not to NIH/3T3 fibroblasts. The expression level of three unknown clones were glucose-concentration dependent. Combination of a random cDNA sequencing approach and Northern blot analysis is useful to obtain a large number of novel genes and islet beta-cell-related genes. [Diabetologia (1995) 38: 381-386]

Key words Random cDNA sequencing, MIN6, pancreatic islet beta cell.
Understanding the molecular basis of pancreatic islet beta cells is essential in order to develop a logical treatment for diabetes. In addition to glucokinase [1-3] and mitochondrial genes [4-5], which are known to be aetiological for non-insulin-dependent diabetes or maturity-onset diabetes of the young, there are others which are related to islet beta-cell

Received: 12July 1994 and in revised form: 20 September 1994

Corresponding author: Professor M.Itakura, Otsuka Department of Clinical and Molecular Nutrition, School of Medicine, University of Tokushima, Kuromoto, Tokushima-city, Tokushima, 770, Japan

Abbreviations: DMEM, Dulbecco's modified Eagle's medium; FCS, fetal calf serum; AGPC, acid guanidinium thiocyanatephenol-chloroform; bp, base pair(s); IAPP, islet amyloid polypeptide; HUMMHBA 123, human MHC protein homologous to chicken $\mathrm{B}$ complex protein; PACAP, pituitary adenylate cyclase activating polypeptide precursor. function and diabetes. It is speculated that the highly-differentiated functions of islet beta cells are based on a group of cell-specific genes. Recently, large-scale cDNA analysis has become a valuable way to examine and register expressed genes in various tissues by determining expressed sequence tags [6-9]. Abundant transcripts, which are frequently encountered in random sequencing, are assumed to play relatively more important roles than rare transcripts with exceptions including transacting factors and rate-limiting enzymes among others. With this in mind we randomly sequenced cDNA to clone unknown genes which are abundantly expressed and are presumably important for islet beta-cell functions. In this study we report the acquisition of a group of islet beta-cell-related genes by combining a random cDNA sequencing of a total of 1,773 clones from a mouse islet beta-cell line of MIN6 [10] with Northern blot analysis of 448 clones. 


\section{Materials and methods}

Cell preparation. A mouse islet beta-cell line of MIN6 (passage 17-20), established from a transgenic mouse harbouring an insulin promoter plus Simian mouse virus (SV)40 T-antigen fusion construct, was cultured up to $70-80 \%$ confluency in Dulbecco's modified Eagle's medium (DMEM) containing $25 \mathrm{mmol} / 1$ glucose and $10 \%$ fetal calf serum (FCS). Cells were then cultured in $10 \%$ FCS and DMEM for $12 \mathrm{~h}$ under either high glucose $(25 \mathrm{mmol} / \mathrm{l})$ or low glucose $(0.5 \mathrm{mmol} / \mathrm{l})$ conditions.

cDNA library construction. RNA was extracted from MIN6 cells by the acid guanidinium thiocyanate-phenol-chloroform (AGPC) method [11]. Five micrograms of poly (A) ${ }^{+}$RNA was incubated with $200 \mathrm{pmol}$ of XhoI-(dT) $)_{15}$ primer (ATTAACCTCAGCCACTCGAGTTTTTTTTTTTTTTT), $1 \mathrm{mmol} / 12$-mercaptoethanol, $500 \mu \mathrm{mol} / 1$ each of dNTPs, $200 \mathrm{U}$ of RNasin (Promega Madison, WI, USA), $100 \mathrm{U}$ of Avian myeloblastosis virus (AMV) reverse transcriptase (Seikagaku Corporation Chuo-ku, Tokyo, Japan), $50 \mathrm{mmol} / \mathrm{l}$ Tris-HCl ( $\mathrm{pH}$ $8.5), 8 \mathrm{mmol} / 1 \mathrm{MgCl}_{2}, 30 \mathrm{mmol} / \mathrm{l} \mathrm{KCl}$ at $37^{\circ} \mathrm{C}$ for $1 \mathrm{~h}$. It was then incubated with $50 \mathrm{U}$ of Escherichia coli DNA polymerase I, $3 \mathrm{U}$ of RNase $\mathrm{H}, 500 \mu \mathrm{mol} / \mathrm{l}$ each of dNTPs, $50 \mathrm{mmol} / \mathrm{l}$ Tris- $\mathrm{HCl}(\mathrm{pH} \mathrm{7.5}), 10 \mathrm{mmol} / 1 \mathrm{MgCl}_{2}, 1 \mathrm{mmol} / 1$ 2-mercaptoethanol, and $90 \mathrm{mmol} / \mathrm{KCl}$ at $14^{\circ} \mathrm{C}$ for $1 \mathrm{~h}$, then at $22^{\circ} \mathrm{C}$ for $1 \mathrm{~h}$. It was incubated with $10 \mathrm{U}$ of $\mathrm{T} 4 \mathrm{DNA}$ polymerase at $37^{\circ} \mathrm{C}$ for $10 \mathrm{~min}$. The product was eluted by centrifugation with a Chroma spin column S-400 (Clontech Palo Alto, CA, USA) at $700 \times g$ for $5 \mathrm{~min}$.

An Eco RI adaptor was ligated to cDNA following the recommendations of Takara (Otsu, Shiga, Japan). After digestion with $X h o I$, the product was eluted with a Chroma spin column. The $5^{\prime}$ end of the cDNA was phosphorylated with $10 \mathrm{U}$ of T4 polynucleotide kinase and $100 \mu \mathrm{mol} / 1$ of $\mathrm{ATP}$ at $37^{\circ} \mathrm{C}$ for $30 \mathrm{~min}$. One microgram of $\lambda$-ZAPII arms (Stratagene, La Jolla, CA, USA) double-digested with $X h o I$ and Eco RI was ligated to the cDNA using a Takara ligation kit. Phage packaging was done with the Gigapack II Gold (Stratagene), following the protocol recommended by the manufacturer.

Converting phage clones en masse to pBluescripts. The E. coli strain XL1-Blue infected with about 5,000 phage clones were incubated in Luria-Bertari (LB) top agar at $37^{\circ} \mathrm{C}$ overnight. Eluted $\lambda$-ZAPII phages were converted en masse to pBluescript SK (-), using R408 helper phage, following the protocol recommended by Stratagene.

Random single pass sequencing. Randomly selected colonies were incubated in LB medium with $50 \mu \mathrm{g} / \mathrm{ml}$ of ampicillin at $37^{\circ} \mathrm{C}$ overnight. The pBluescript DNA was extracted using the alkaline lysis method. Sequencing of the inserts were performed with $\mathrm{ABI} 373 \mathrm{~A}$ autosequencer (Applied Biosystems, Foster, CA, USA) with a dye-labelled T7 or T3 primer, following the manufacturer's protocol.

Northern blot analysis. RNA was extracted by the AGPC method from MIN6 cells cultured in high or low glucose media, NIH/3T3 fibroblasts, and organs of C57BL/6 mice including brain, liver, spleen, kidney, and pancreas. Twelve micrograms each of total RNA was electrophoresed through a $1 \%$ denaturing agarose gel and was transferred to Hybond-N (Amersham, Buckinghamshire, England). To make probes, each diluted pBluescript insert was amplified by polymerase chain reaction (PCR) at $94^{\circ} \mathrm{C}$ for $1 \mathrm{~min}, 50^{\circ} \mathrm{C}$ for $1 \mathrm{~min}, 72^{\circ} \mathrm{C}$ for $2 \mathrm{~min}$, after 40 cycles with $30 \mathrm{pmol}$ of SK and $\mathrm{T} 7$ primers. Free nucleotides were removed using glass powder. The labelling by $\alpha^{32} \mathrm{P}$ dCTP was performed by the multiprime labelling system (Amersham). The hybridization was performed in $50 \%$ formamide, $5 \times \mathrm{SSPE}$ buffer, $5 \times$ Denhardt's reagent, and $0.5 \% \mathrm{SDS}$ at $42^{\circ} \mathrm{C}$ overnight. Membrane was washed three
(A)

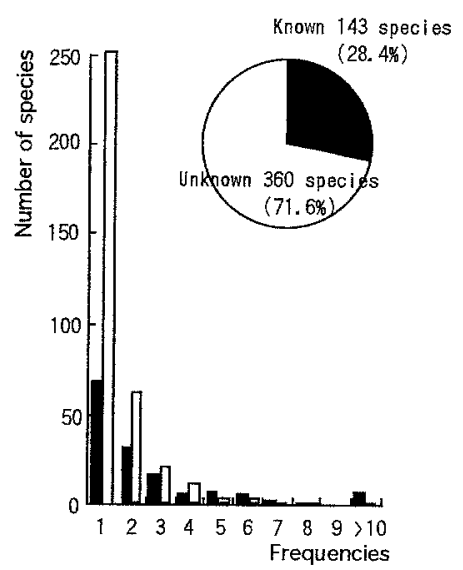

(B)

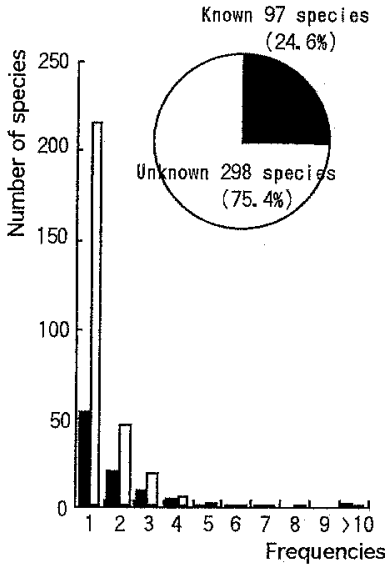

Fig.1A, B. Relationship between known and unknown genes, and between frequencies of appearance and the number of species. (A) In the high glucose library, a total of 1,011 clones were computer-searched, and 503 independent species were obtained, among which $143(28.4 \%)$ and $360(71.6 \%)$ species were known and unknown genes, respectively. Relationship between frequencies of appearance and the number of species of known ( $\mathbf{a})$ and unknown genes ( $\square$ ) is shown. Genes with frequencies of more than ten times $(>10)$ were 6 and 1 species in the known and unknown genes, respectively. (B) In the low glucose library, $97(24.6 \%)$ and $298(75.4 \%)$ species were known and unknown, respectively. The number of known and unknown species decreased along with the increasing frequencies of appearance in both libraries

times with $1 \times$ SSPE and $0.1 \%$ SDS at $65^{\circ} \mathrm{C}$ for 30 min, and exposed for autoradiography on Kodak XAR film (Rochester, New York, USA) for $2-72 \mathrm{~h}$ at $-80^{\circ} \mathrm{C}$.

\section{Results}

Analysis of randomly-sequenced $c D N A$. A pair of cDNA libraries was separately constructed from a mouse MIN6 pancreatic islet beta-cell line, which was cultured in high or low glucose media. The sizes of inserts of randomly-selected clones ranged from zero to about 2,000 base pairs (bp) with an average of $800 \mathrm{bp}$. The randomly-selected clones from the high glucose and low glucose library were directionally sequenced from the 3 '-end with a dye-labelled T7 primer, using a fluorescence-based DNA autosequencer. Only when cDNA sequences were not readable from the 3 '-end due to a long poly(A) tail, they were sequenced with a dye-labelled $\mathrm{T} 3$ primer from the 5 -end. The average length of compiled sequences of inserts was $252 \mathrm{bp}$. The clones with inserts of less than $60 \mathrm{bp}$ were eliminated, because the longer sequence supplies more information about its identity than a fragmentary cDNA. Finally, a total of 1,011 and 762 clones were sequenced from the high glucose and low glucose library, respectively. The sequence similarities of 1,773 clones were first 
Table 1. Summary of known genes in random sequencing. Frequencies of appearance of representative known genes in the random sequencing are listed

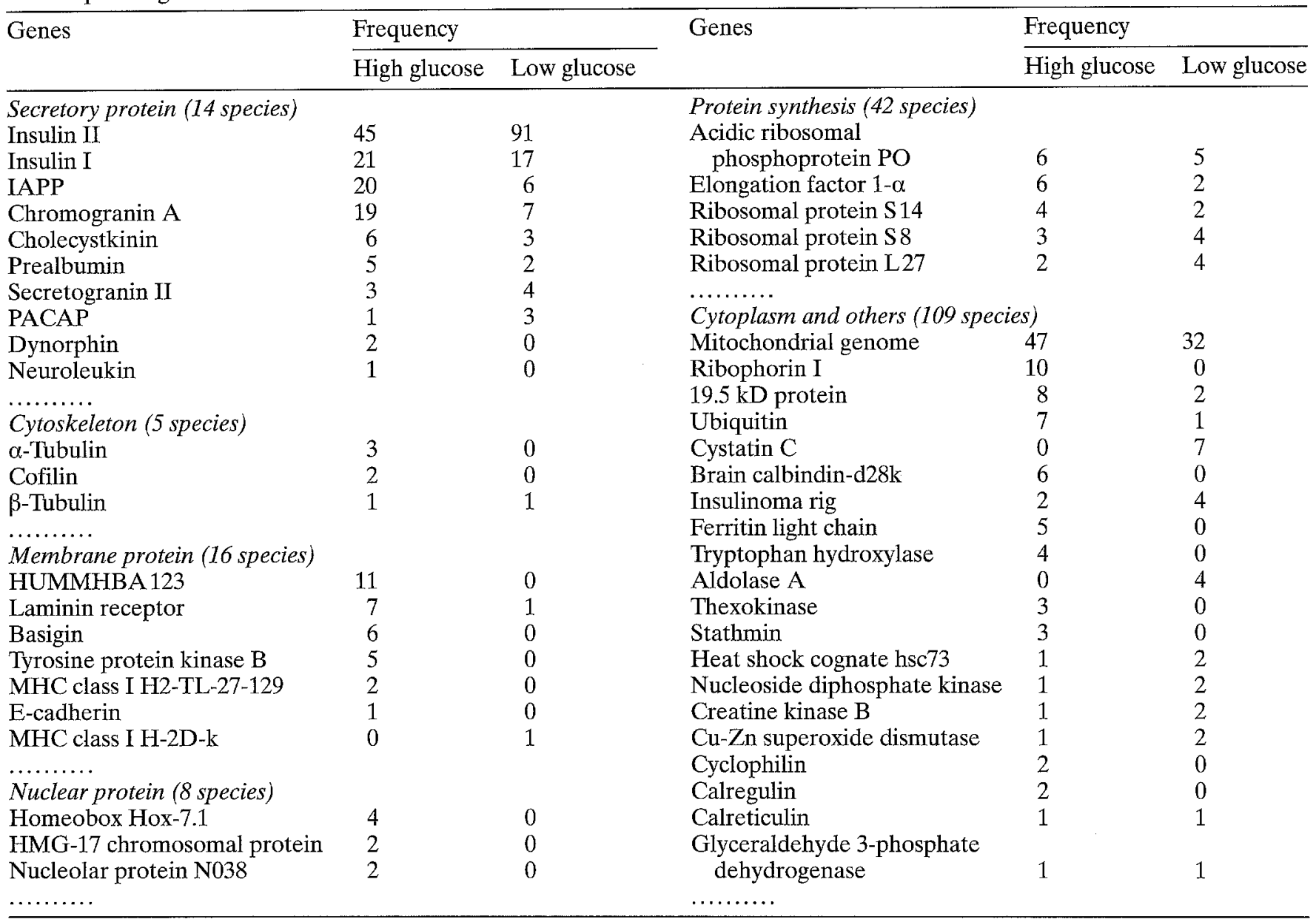

compared with each other and then with the DNA data base in GenBank Bethesda, MD, USA (Release 80.0 December, 1993) encompassing mammalian genes, using a FASTA program $[12,13]$. Genes with more than a $90 \%$ similarity with the known genes in GenBank were defined as known, while others were defined as unknown. We obtained 503 and 395 independent species in the high glucose and low glucose library, respectively. Known genes comprised the minority of $143(28.4 \%)$ and 97 clones $(24.6 \%)$ in the high glucose and low glucose library, respectively (Fig. 1).

Most known and unknown genes appeared once and the number of known and unknown genes exponentially decreased along with the increasing frequency of appearance in both libraries (Fig.1). The genes with an appearance rate of more than $1 \%$ were numbers 7 and 4 in the high glucose and low glucose library, respectively. Appearance rates for insulin I [14] of $2.1 \%$ and mitochondrial genome [15] of $4.6 \%$ in the high glucose library were comparable to those of 2.2 and $4.2 \%$ in the low glucose library, while those for insulin II of $4.5 \%$, islet amyloid polypeptide (IAPP) [16] of $2.0 \%$, chromogranin A of
$1.9 \%$, and human $\mathrm{MHC}$ protein homologous to chicken B complex protein (HUMMHBA 123) of $1.1 \%$ in the high glucose library were apparently different from $11.9,0.8,0.9$, and $0 \%$ in the low glucose library, respectively. Clones of insulin II, insulin I, and IAPP had poly(A) tails of different lengths ranging from 0 to about 120 daltons, which suggested the different origins of each clone. On the other hand, chromogranin A and HUMMHBA 123 had no poly(A) tails, which suggested the presence of Xho I site in the sequence.

We categorized known genes to 'secretory protein', 'cytoskeleton', 'membrane protein', 'nuclear protein', 'protein synthesis', 'cytoplasm and others', although most of their precise functions are unknown (Table 1). In 'secretory protein', cholecystokinin, prealbumin, secretogranin II, and pituitary adenylate cyclase activating polypeptide precursor (PA$\mathrm{CAP}$ ) in addition to insulin, IAPP, and chromograni$\mathrm{n}$ A were found in both libraries. The protein-synthesis-related genes were composed of as many as 42 species. There were another 109 species including proteasome, ATPases, kinases, etc., and those with unknown functions. Only 60 species $(15.2 \%)$ of the 


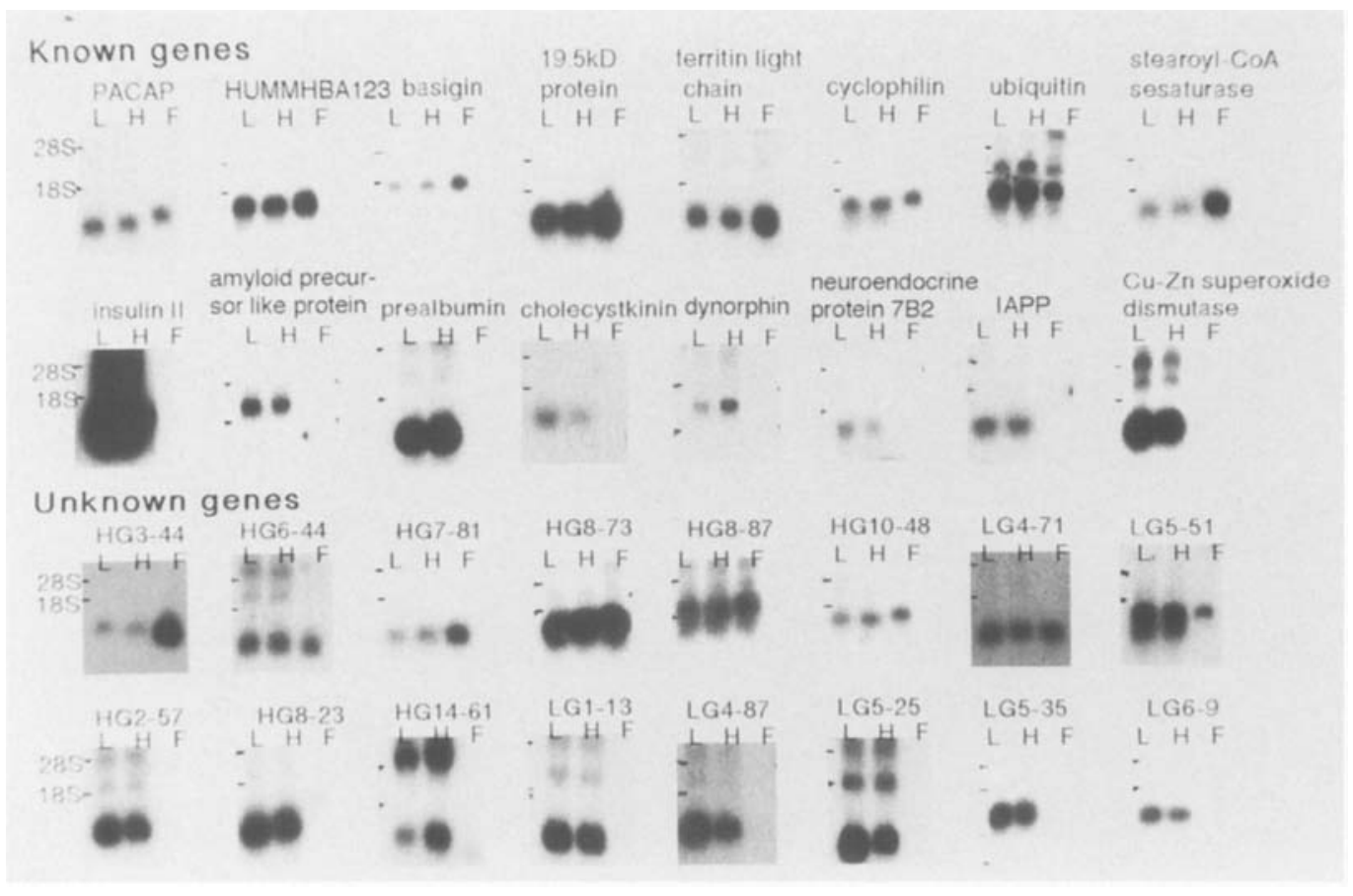

Fig. 2. Northern blot analysis to obtain MIN6-related clones. We hybridized 448 independent clones with $12 \mu \mathrm{g}$ of total RNA of MIN6 cells, which were cultured under low or high glucose conditions and that of NIH/3T3 fibroblasts, as abbreviated, $\mathrm{L}$, $\mathrm{H}$, and $\mathrm{F}$, respectively. Exposure was for 2-72 h. Top and second rows, eight representative known genes commonly expressed in MIN6 cells and $\mathrm{NIH} / 3 \mathrm{~T} 3$ fibroblasts, and those expressed in only MIN6 cells are shown, respectively. On the third and bottom rows, the unknown clones commonly expressed in both cell lines, and those expressed in only MIN6 cells are shown, respectively low glucose library overlapped those of the high glucose library.

Northern blot analysis to explore cell-specific and glucose concentration-responsive expression. For the first screening, gene expression and sizes of transcripts were examined by Northern blot analysis in regard to the specificity to MIN6 cells or NIH/3T3 fibroblasts, and regarding responsiveness to the high glucose or low glucose metabolic conditions. A total of 448 independent clones including 110 known and 204 unknown clones in the high glucose library, and 17 known and 117 unknown clones in the low glucose library, were used as ${ }^{32} \mathrm{P}$ labelled probes. A total of 311 probes $(69.4 \%)$ showed positive signals within $72 \mathrm{~h}$ of autographic exposure. A total of 150 (48.2\%) clones including 43 known and 107 unknown genes hybridized to MIN6 transcripts but not to those of NIH/3T3 fibroblasts. A total of 158 (50.8\%) clones including 63 known and 95 unknown genes hybridized to both MIN6 and NIH/3T3 transcripts. Three other clones showed positive signals to NIH/3T3 transcripts, but not to those of MIN6. Most positive genes in MIN6 hybridized to both high glucose and low glucose transcripts at the same intensity. Three unknown genes were glucose concentration-responsive. The HG14-61 found in the high glucose library showed a stronger signal to high glucose transcripts, while LG4-87 and LG5-25 found in the low glucose library showed stronger signals to low glucose transcripts, compared with other known genes used as control (Fig. 2).

To confirm the organ specificity, the clones, which showed a positive signal to MIN6 cells, but not to $\mathrm{NIH} / 3 \mathrm{~T} 3$ fibroblasts, were further analysed using
RNA extracted from various organs from C57BL/6 mice including brain, liver, spleen, kidney, and pancreas. Eleven of 16 clones so far examined showed a weak signal to pancreatic RNA, but did not show any signals to RNA of other organs (Fig. 3).

\section{Discussion}

To obtain pancreatic islet beta-cell-specific genes and glucose concentration-responsive genes, we constructed a pair of MIN6 cDNA libraries which were cultured in high glucose or low glucose media. MIN6 (passage 17-20) secreted insulin about 3, 4 and 6 times more in $5,15,25 \mathrm{mmol} / \mathrm{l}$ than in $0.5 \mathrm{mmol} / 1$ glucose for $12 \mathrm{~h}$, respectively (data not shown). We assumed that some controlling genes which were involved in insulin synthesis and secretion during the relatively early stage, could be obtained by comparing cDNA from MIN6 incubated for $12 \mathrm{~h}$ in 0.5 and $25 \mathrm{mmol} / \mathrm{l}$ glucose.

Our random cDNA sequencing firstly enabled us to observe the genetic pattern of expressed genes in islet beta cells. A mammalian cell is assumed to express genes of as many as 15,000-30,000 species out of a presumed total of 50,000-100,000 genes. In our random sequencing of 1,773 clones, the majority of cDNA clones appeared once and the number of species decreased exponentially along with the increasing frequency of appearance. This is consistent with the concept that a great variety of genes are expressed in relatively low abundance in vivo, and it showed that our libraries included enough species of gene for random cDNA sequencing. 


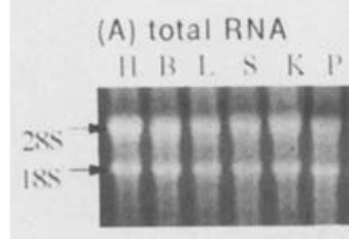

(D) HG10-84

(B) $\mathrm{HG} 2-57$ II B I. S K P

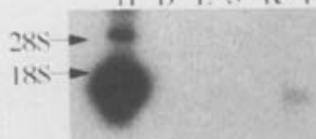

(C) HG3-72

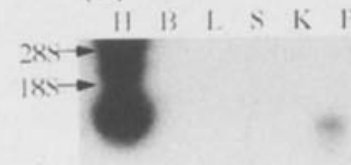

Fig.3. (A-F) Gene expression in various organs. Unknown genes, which showed positive signals only to MIN6 cells but not to NIH/3T3 fibroblasts, were examined regarding organ specificity by Northern blot analysis. (A) Twelve micrograms each of total RNA was electrophoresed through a $1 \%$ denaturing agarose gel. (B)-(D) Eleven of 16 clones showed weak positive signals to RNA of the pancreas but not to those of other organs. For example, HG2-57, HG3-72 and HG10-84 showed strong signals to MIN6, weak positive signals to the pancreas, but not to other organs at $72 \mathrm{~h}$ of autoradiographic exposure. (E) LG3-12 showed a positive signal to all of the organs at $6 \mathrm{~h}$ of exposure. (F) Insulin II showed a signal to the pancreas at 6 h. H, B, L, S, K, and P stand for MIN6 cells cultured under high glucose conditions, brain, liver, spleen, kidney, and pancreas of C57BL/6 mice, respectively

Insulin is one of the most important genes in islet beta cells, and the appearance rate of insulin II was actually the highest in the libraries except for mitochondrial genes, which comprised many genes including tRNA, rRNA, ATPase, among others. Appearance rates in the random sequencing should generally reflect abundance of transcripts in vivo, but the reflection is not perfect. Appearance rates of insuli$\mathrm{n}$ II, chromogranin A and IAPP among others in the high glucose library were apparently different from those in the low glucose library. Because signals of those transcripts in Northern blot analysis were comparable between high glucose and low glucose conditions the differences in the appearance rate may be within the statistically insignificant error range. Our goal is not such a precise estimation of transcripts, but to obtain islet beta-cell-specific and glucose-concentration-responsive genes. Only 60 clones $(15.2 \%)$ from the low glucose library overlapped those of the high glucose library. This, however, does not suggest a large difference in the transcript species between low glucose and high glucose conditions. The number of common genes should increase, as the number of clones in random sequencing is increased.
Recently, random cDNA sequencing of human pancreatic islets containing a mixture of cells was reported [17]. Only $17(9.9 \%)$ of the 172 known genes reported overlapped those of ours. The $9.9 \%$ value is reasonable, considering the difference between the libraries; ours with inserts of more than $400 \mathrm{bp}$ from a pure mouse islet beta-cell line and the reported library with inserts of more than $1,000 \mathrm{bp}$ from various human islet cells, and considering the similar proportion of $15.2 \%$ overlapped genes between our high glucose and low glucose libraries.

Secondly, cell- and metabolic condition-related genes were extracted using extensive Northern blot analysis. To our surprise, $150(48.2 \%)$ species of 311 positive genes only showed positive signals to MIN6 cells, but not to NIH/3T3 fibroblasts. These were candidate genes specifically expressed in islet beta cells. The generally accepted idea that transcripts specific for a particular cell are relatively small in number and that most transcripts are of house-keeping genes, was not the case for islet beta cells. Rather, islet beta cells with a highly differentiated ability to secrete insulin are regarded as being based on a large number of cell-specific genes. Because the majority of clones, which showed positive signals to MIN6 cells but not to NIH/3T3 fibroblasts at the first screening, showed weak positive signals to transcripts of pancreas but not to those of other organs, they were likely to be specifically expressed in islet beta cells in vivo. Because islet beta cells comprise a small percentage of the pancreas, it is reasonable that signals from islet beta-cell-specific genes are weak to the RNA extracted from the whole pancreas. In Northern blotting, there were only three glucose concentration-responsive genes, but insulin was not included among them. It has been suggested that insulin is regulated by translational rather than transcriptional control.

To obtain cell-specific clones, many subtraction procedures have been used [18-20]. Because one in every two or three clones was a candidate gene specific to islet beta cells in our random cDNA sequencing approach, one does not need a subtraction to obtain islet beta-cell specific genes.

By the combination of a random cDNA sequencing approach and Northern blot analysis using fibroblasts as a control, a large number of unknown pancreatic beta-cell-related clones were obtained from a cultured islet beta-cell line. Although the final characterization has not been completed, our exhaustive efforts to obtain cell-specific and metabolic condition-responsive genes supplied us with a large number of candidate genes. To explore the significance of these genes in islet beta-cell function and diabetes, Northern blot analysis including other neuroendocrine cells, in situ hybridization, and functional analysis are underway in addition to complete sequencing. 
Acknowledgements. This study was supported in part by a grant from Otsuka Pharmaceutical Factory Inc. We thank E. Adachi and Y.Mitani for their technical help, and Dr. J.Miyazaki for supplying the MIN6 cells.

\section{References}

1. Froguel Ph, Vaxillaire M, Sun F et al. (1992) Close linkage of glucokinase locus on chromosome $7 p$ to early-onset noninsulin-dependent diabetes mellitus. Nature 356: 162-164

2. Hattersley AT, Turner RC, Permutt MA et al. (1992) Linkage of type 2 diabetes to the glucokinase gene. Lancet 339 : 1307-1310

3. Vionnet N, Stoffel M, Takeda J et al. (1992) Nonsense mutation in the glucokinase gene causes early-onset non-insulin-dependent diabetes mellitus. Nature 356: 721-722

4. Ballinger SW, Shoffner JM, Hedaya EV et al. (1992) Maternally transmitted diabetes and deafness associated with a $10.4 \mathrm{~kb}$ mitochondrial DNA deletion. Nature Genet 1: 1115

5. van den Quweland JMW, Lemkes HHPJ, Ruitenbeek W et al. (1992) Mutation in mitochondrial tRNA gene in a large pedigree with maternally transmitted type II diabetes mellitus and deafness. Nature Genet 1: 368-371

6. Okubo K, Hori N, Matoba R et al. (1992) Large scale cDNA sequencing for analysis of quantitative and qualitative aspects of gene expression. Nature Genet 2: 173-179

7. Okubo K, Hori N, Matoba R et al. (1991) A novel system for large-scale sequencing of cDNA by PCR amplification. DNA Sequence 2: 137-144

8. Adams MD, Kerlavage AR, Fields Cet al. (1993) 3,400 new expressed sequence tags identify diversity of transcripts in human brain. Nature Genet 4: 256-267

9. Adams MD, Kelley JM, Gocayne MD et al. (1991) Complementary DNA sequencing: expressed sequence tags and human genome project. Science 252: 1651-1656
10. Miyazaki J, Araki K, Yamato E, Ikegami H et al. (1990) Establishment of a pancreatic $\beta$ cell line that retains glucoseinducible insulin secretion: special reference to expression of glucose transporter isoforms. Endocrinology 127: 126132

11. Xie W, Rothblum LI (1991) Rapid, small scale RNA isolation from tissue culture cells. BioTechniques 11: 125-127

12. Pearson WR, Lipman DJ (1988) Improved tools for biological sequence comparison. Proc Natl Acad Sci USA 85: 2444-2448

13. Lipman DJ, Pearson WR (1985) Rapid and sensitive protein similarity searches. Science 227: 1435-1441

14. Wentworth BM, Schaefer IM, Villa-Komaroff L et al. (1986) Characterization of the two nonallelic genes encoding mouse preproinsulin. J Mol Evol 23: 305-312

15. Bibb MJ, van Etten RA, Wright CT et al. (1981) Sequence and gene organization of mouse mitochondrial DNA. Cell 26: $167-180$

16. Nishi M, Chan SJ, Nagamatsu S et al. (1989) Conservation of the sequence of islet amyloid polypeptide in five mammals is consistent with its putative role as an islet hormone. Proc Natl Acad Sci USA 86: 5738-5742

17. Takeda J, Yano H, Eng S et al. (1993) A molecular inventory of human pancreatic islets: sequence analysis of 1000 cDNA clones. Human Molecular Genetics 2: 17931798

18. Hara E, Kato T, Nakada S et al. (1991) Subtractive cDNA cloning using Oligo(dT) ${ }_{30}$-latex and PCR: isolation of cDNA clones specific to undifferentiated human embryonic carcinoma cells. Nucl Acids Res 25: 7097-7104

19. Lisitsyn N, Lisitsyn N, Wigler M (1993) Cloning the differences between two complex genomes. Science 259: 946 951

20. Liang P, Pardee AB (1992) Differential display of eukaryotic messenger by means of the polymerase chain reaction. Science 257: $967-971$ 